\title{
A novel alteration in metaxin 1, F202L, is associated with N370S in Gaucher disease
}

Received: 25 August 2003/ Accepted: 18 January 2004 / Published online: 13 March 2004

(C) The Japan Society of Human Genetics and Springer-Verlag 2004

\begin{abstract}
The gene for glucocerebrosidase $(G B A)$, the enzyme deficient in Gaucher disease, is located in a generich region on 1q21. Metaxin $1(M T X 1)$ is a convergently transcribed gene contiguous to the $3^{\prime}$ end of the $G B A$ pseudogene. A single nucleotide alteration in MTX1, $628 \mathrm{~T} \rightarrow \mathrm{C}$, resulting in the amino acid change F202L, was identified in patients with Gaucher disease in association with the common N370S mutation in $G B A$. The polymorphism was also present on $4.6 \%$ of 152 control alleles, but could have functional consequences that have a modifying role in Gaucher disease.
\end{abstract}

Keywords Gaucher disease - Genotype/phenotype correlation - Glucocerebrosidase - Haplotype ·

Metaxin · Polymorphism

\section{Introduction}

Gaucher disease, the inherited deficiency of glucocerebrosidase (EC 3.2.1.45), manifests with vast phenotypic variation. Studies of genotype/phenotype correlation in this disorder increasingly implicate the contribution of genetic modifiers (Dipple and McCabe2000; Koprivica

M. E. LaMarca $\cdot$ M. Goldstein $\cdot$ N. Tayebi $\cdot$ M. Arcos-Burgos E. Sidransky

Medical Genetics Branch,

National Human Genome Research Institute,

Bethesda, MD, 20892-4405 USA

M. E. LaMarca $\cdot$ M. Goldstein · N. Tayebi · E. Sidransky $(\bowtie)$

Section on Molecular Neurogenetics,

National Institute of Mental Health,

49 Convent Drive MSC4405, 49/B1EE16,

Bethesda, MD 20892-4405, USA

E-mail: sidranse@irp.nimh.nih.gov

Tel.: + 1-301-4960373

Fax: + 1-301-4026438

B. M. Martin

Laboratory of Neurotoxicology,

National Institute of Mental Health,

Bethesda, MD, 20892-4405 USA et al. 2000; Park et al. 2003). The region of chromosome 1q21 encompassing the human glucocerebrosidase gene $(G B A)$ is particularly gene rich, with seven genes and two pseudogenes located within $85 \mathrm{~kb}$ of sequence (Long et al. 1996; Winfield et al. 1997). The closest gene to $G B A$ is metaxin 1 (MTX1), a convergently transcribed novel gene contiguous to the $3^{\prime}$ end of the $G B A$ pseudogene (Fig. 1). Metaxin 1 has been localized to the outer mitochondrial membrane and is hypothesized to be part of the preprotein-import complex (Armstrong et al. 1997; Abdul et al. 2000). A pseudogene for metaxin 1 is located in the $16-\mathrm{kb}$ region between $G B A$ and its pseudogene. A mouse knockout for Mtxl resulted in an embryonic lethal phenotype, suggesting that the gene is essential in development (Bornstein et al. 1995). Because of its close proximity and potentially interesting function, we explored whether the gene for metaxin 1 was altered in patients with Gaucher disease with diverse manifestations and whether it might be a genetic modifier in this disorder.

\section{Materials and methods}

Genomic DNA was isolated from white blood cells, fibroblasts, or lymphoblasts obtained with informed consent from patients with Gaucher disease and from normal controls, under an Institute Review Board-approved NIH protocol. Mutations in the gene for glucocerebrosidase were identified as previously described (Koprivica et al. 2000).

Exonic and partial intronic sequences of $M T X 1$ were amplified using PCR and sequenced using a BigDye dye terminator kit (Applied Biosystems) on an ABI 310 or 3100 automated capillary DNA sequencer. A 2.4-kb fragment comprising exons 4-8 was amplified using the forward primer 5'-GCATTGGGCGCTGGACCTTC-3' and the reverse primer 5'-GCGTGAGCTTACAGCGACGTA-3'. Exon 7 was sequenced in both the forward and reverse direction with the forward primer $5^{\prime}$ GCCTGCTGCCCAGAGCCC- $3^{\prime}$ and the reverse primer $5^{\prime}$ AACTAGTTCTTGGATCCCTG- $3^{\prime}$.

Genotype results were analyzed to determine whether the data fit Hardy-Weinberg expected proportions and whether there was genetic disequilibrium between the GBA N370S and MTX1 F202L sites using the Genetic Data Analysis software package (Lewis and Zaykin 2001). 
Fig. 1 The glucocerebrosidase locus, showing the relative positions of the $G B A \mathrm{~N} 370 \mathrm{~S}$ and $M T X 1$ F202L mutations. Polymorphic loci involved in the N370S haplotype are indicated by a downwardpointing arrowhead

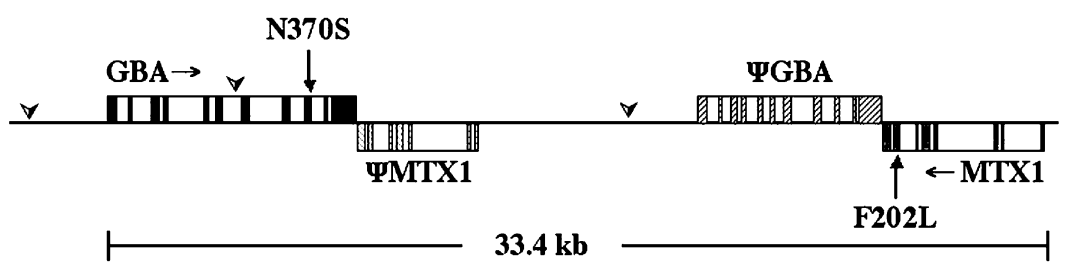

\section{Results and discussion}

Initial sequencing of the complete exonic sequence of $M T X 1$ in eight patients identified a $\mathrm{T} \rightarrow \mathrm{C}$ alteration in six patients at cDNA position 628 in exon 7 (Long et al. 1996), resulting in the amino acid change F202L. It was noted that the MTX1 F202L change occurred only in those patients with a $G B A \mathrm{~N} 370 \mathrm{~S}$ allele, and was homozygous in two N370S homozygotes. To determine the frequency of MTX1 F202L, DNA from 76 control individuals of either Ashkenazi or non-Ashkenazi backgrounds were screened using PCR amplification and direct sequencing of exon 7 of MTX1. Seven of 152 alleles $(4.6 \%)$ were identified with MTX1 F202L (Table 1). None of the seven carried the GBA N370S mutation. Screening of genomic DNA from 90 patients with Gaucher disease (including the original eight) showed that in $25 \mathrm{~N} 370 \mathrm{~S}$ homozygotes, the MTX1 F202L was coallelic in 49 of 50 alleles $(98.0 \%$ ) (Table 1). Moreover, in $53 \mathrm{~N} 370 \mathrm{~S}$ heterozygotes, MTX1 F202L was present on 51 of 106 alleles $(48.0 \%)$. Although it was not determined if the MTX1 F202L was on the same chromosome as the GBA N370S in the heterozygotes, the relative frequency is consistent with the two mutations being co-allelic. Twelve additional patients without N370S all lacked MTX1 F202L. Clinical records for the four patients carrying $G B A \mathrm{~N} 370 \mathrm{~S}$ alleles without MTX1 F202L were reviewed. All four were females with mild to moderately severe manifestations of type 1 Gaucher disease, but without atypical symptoms or disease progression.
Tests for genetic disequilibrium between the N370S and F202L loci using unphased genotype data demonstrated strong deviations from random assortment with a $P$-value $<0.00000$. The disequilibrium was not the result of Hardy-Weinberg deviations.

Twelve polymorphic sites in glucocerebrosidase have been reported, although only two major haplotypes, $P v l .1^{+}$and $P v 1.1^{-}$, have been described in Caucasians (Beutler et al. 1992). Linkage disequilibrium between mutation N370S and the Pvl.1 $1^{-}$haplotype and two other two polymorphic repeat sequences in the glucocerebrosidase gene region, 5GC $3.2(\mathrm{CT})_{40}$ and ITCG.2 (AAAT), have been reported (Zimran et al. 1990; Lau et al. 1999). In the 26 patients in the present study for whom polymorphism data at the 5GC $3.2, P v 1.1$, and ITCG.2 loci were available (Lau et al. 1999), 11 who were homozygous for the reported N370S haplotype were also homozygous for MTX1 F202L, and 13 N370S haplotype heterozygotes also carried an F202L allele. Two patients with N370S alleles had haplotype variations. One, an N370S homozygote, lacked the F202L on one N370S allele and was also heterozygous at the ITCG.2 polymorphic site. The other, an N370S heterozygote, carried the F202L alteration on both alleles but was homozygous for a variant form of the 5GC 3.2 polymorphism. Previous studies report that the N370S mutation has a conserved haplotype on 1q21 in the Ashkenazi Jewish population, supporting the origin of this mutation from a single founder (Diaz et al. 2000). The finding that the majority of N370S alleles are also associated with MTX1 F202L suggests that this alteration may have occurred on the
Table 1 Frequency of the MTX1 F202L mutation in individuals with Gaucher disease and in normal controls. $w t$ Wild type

\footnotetext{
${ }^{\mathrm{a}}$ Known glucocerebrosidase mutations excluding N370S
}

\begin{tabular}{|c|c|c|c|c|c|}
\hline \multirow{2}{*}{$\begin{array}{l}G B A \\
\text { genotype }\end{array}$} & \multirow[t]{2}{*}{ Ethnicity } & \multirow{2}{*}{$\begin{array}{l}\text { Sample } \\
\text { size }(n)\end{array}$} & \multicolumn{3}{|c|}{$M T X$ lgenotype } \\
\hline & & & wt/wt & F202L/wt & F202L/F202L \\
\hline \multicolumn{6}{|l|}{ Patients } \\
\hline \multirow{3}{*}{ N370S/N370S } & Ashkenazi & 24 & 0 & 1 & 23 \\
\hline & Non-Ashkenazi & 1 & 0 & 0 & 1 \\
\hline & Total & 25 & 0 & 1 & 24 \\
\hline \multirow[t]{3}{*}{ N370S/other ${ }^{\mathrm{a}}$} & Ashkenazi & 18 & 1 & 16 & 1 \\
\hline & Non-Ashkenazi & 35 & 2 & 33 & 0 \\
\hline & Total & 53 & 3 & 49 & 1 \\
\hline \multirow{3}{*}{ Other/other } & Ashkenazi & 2 & 2 & 0 & 0 \\
\hline & Non-Ashkenazi & 10 & 10 & 0 & 0 \\
\hline & Total & 12 & 12 & 0 & 0 \\
\hline \multirow{4}{*}{$\begin{array}{l}\text { Normal controls } \\
\mathrm{wt} / \mathrm{wt}\end{array}$} & & & & & \\
\hline & Ashkenazi . & 36 & 33 & 3 & 0 \\
\hline & Non-Ashkenazi & 40 & 36 & 4 & 0 \\
\hline & Total & 76 & 69 & 7 & 0 \\
\hline
\end{tabular}


same ancestral allele. Of note, neither the N370S nor the F202L mutations are found in their respective pseudogenes.

Although F202L in metaxin 1 is a polymorphism, there could be possible functional consequences of this finding. All patients carrying the Gaucher N370S mutation are known to have type 1, non-neuronopathic Gaucher disease (Beutler and Grabowski2001). The mechanisms for the neuroprotective effect of N370S are not altogether clear, since the factors determining whether neuronopathic Gaucher disease will develop are not fully understood. Moreover, attempts to generate a point-mutation mouse model with mutation N370S have unexpectedly led to a neonatal lethal phenotype (Zhao and Grabowski2002). Murine Mtxl does not contain the F202L alteration and also lacks the glucocerebrosidase and metaxinpseudogenes found in humans. One intriguing possibility is that the presence of MTX1 F202L or interactions with the adjacent pseudogenes might somehow modify the burden of disease in patients carrying the N370S Gaucher mutation. A mouse model homozygous for both the Gba N370S and Mtxl F202L mutations may elucidate interactions between the contiguous genes and may determine whether metaxin has a role as a modifier of Gaucher disease.

\section{References}

Abdul KM, Terada K, Yano M, Ryan MT, Streimann I, Hoogenraad NJ, Mori M (2000) Functional analysis of human metaxin in mitochondrial protein import in cultured cells and its relationship with the Tom complex. BiochemBiophys Res Commun 276:1028-1034

Armstrong LC, Komiya T, Bergman BE, Mihara K, Bornstein P (1997) Metaxin is a component of a preprotein import complex in the outer membrane of the mammalian mitochondrion. J BiolChem 272:6510-6518

Beutler E, Grabowski GA (2001) Gaucher disease. In: ScriverCR, BeaudetAL, Valle D, Sly WS (eds) The metabolic and molec- ular bases of inherited disease. McGraw-Hill, New York, pp 3635-3668

Beutler E, West C, Gelbart T (1992) Polymorphisms in the human glucocerebrosidase gene. Genomics 12:795-800

Bornstein P, McKinneyCE, LaMarca ME, Winfield S, Shingu T, Devarayalu S, VosHL, GinnsEI (1995) Metaxin, a gene contiguous to both thrombospondin 3 and glucocerebrosidase, is required for embryonic development in the mouse: implications for Gaucher disease. Proc NatlAcadSci USA 92:4547-4551

Diaz GA, GelbBD, Risch N, NygaardTG, Frisch A, CohenIJ, Miranda CS, Amaral O, Maire I, Poenaru L, Caillaud C, Weizberg M, Mistry P, DesnickRJ (2000) Gaucher disease: the origins of the Ashkenazi Jewish N370S and 84GG acid beta-glucosidase mutations. Am J Hum Genet 66:1821-1832

Dipple KM, McCabeER (2000) Phenotypes of patients with "simple" Mendelian disorders are complex traits: thresholds, modifiers and systems dynamics. Am J Hum Genet 66:17291735

Koprivica V, Stone DL, Park JK, Callahan M, Frisch A, CohenIJ, Tayebi N, Sidransky E (2000) Analysis and classification of 304 mutant alleles in patients with type 1 and type 3 Gaucher disease. Am J Hum Genet 66:1777-1786

Lau EK, Tayebi N, Ingraham LJ, Winfield SL, Koprivica V, Stone DL, Zimran A, Ginns EI, Sidransky E (1999) Two novel polymorphic sequences in the glucocerebrosidase gene region enhance mutational screening and founder effect studies of patients with Gaucher disease. Hum Genet 104:293-300

Lewis PO, ZaykinDV (2001) Genetic data analysis: computer program for the analysis of allelic data. Version 1.0 (d16c). Free program distributed by the authors over the Internet from http://lewis.eeb.uconn.edu/lewishome.software.html

Long GL, Winfield S, Adolph KW, GinnsEI, Bornstein P (1996) Structure and organization of the human metaxin gene $(M T X)$ and pseudogene. Genomics 33:177-184

Park JK, Orvisky E, Tayebi N, Kaneski C, LaMarca ME, StubblefieldBK, Martin BM, Schiffmann R, Sidransky E (2003) Myoclonic epilepsy in Gaucher disease: genotype-phenotype insights from a rare patient subgroup. Pediatr Res 53:387-395

WinfieldSL, Tayebi N, Martin BM, GinnsEI, Sidransky E (1997) Identification of three additional genes contiguous to the glucocerebrosidase locus on chromosome 1q21: implications for Gaucher disease. Genome Res 7:1020-1026

Zhao H, Grabowski GA (2002) Gaucher disease: perspectives on a prototype lysosomal disease. Cell Mol Life Sci 59:694-707

Zimran A, Gelbart T, Beutler E (1990) Linkage of the PvuII polymorphism with the common Jewish mutation for Gaucher disease. Am J Hum Genet 46:902-905 